\title{
RPM Deployment Requirements for State and Local Use
}

Richard Kouzes

Larry Pines

Robert Sitsler

September 2015

\section{Pacific Northwest}

NATIONAL LABORATORY

Proudly Operated by Battelle Since 1965 


\title{
DISCLAIMER
}

This report was prepared as an account of work sponsored by an agency of the United States Government. Neither the United States Government nor any agency thereof, nor Battelle Memorial Institute, nor any of their employees, makes any warranty, express or implied, or assumes any legal liability or responsibility for the accuracy, completeness, or usefulness of any information, apparatus, product, or process disclosed, or represents that its use would not infringe privately owned rights. Reference herein to any specific commercial product, process, or service by trade name, trademark, manufacturer, or otherwise does not necessarily constitute or imply its endorsement, recommendation, or favoring by the United States Government or any agency thereof, or Battelle Memorial Institute. The views and opinions of authors expressed herein do not necessarily state or reflect those of the United States Government or any agency thereof.

\author{
PACIFIC NORTHWEST NATIONAL LABORATORY \\ operated by \\ BATTELLE \\ for the \\ UNITED STATES DEPARTMENT OF ENERGY \\ under Contract DE-AC05-76RL01830
}

Printed in the United States of America

\author{
Available to DOE and DOE contractors from the \\ Office of Scientific and Technical Information, \\ P.O. Box 62, Oak Ridge, TN 37831-0062; \\ ph: (865) 576-8401 \\ fax: (865) 576-5728 \\ email: reports@adonis.osti.gov
}

Available to the public from the National Technical Information Service, U.S. Department of Commerce, 5285 Port Royal Rd., Springfield, VA 22161

ph: (800) 553-6847

fax: (703) 605-6900

email: orders@ntis.fedworld.gov

online ordering: http://www.ntis.gov/ordering.htm 
PNNL-24838

\section{RPM Deployment Requirements for State and Local Use}

Richard Kouzes

Larry Pines

Robert Sitsler

September 2015

Pacific Northwest National Laboratory

Richland, Washington 99352 


\section{Executive Summary}

Radiation Portal Monitors (RPMs) are instruments that passively detect gamma and neutron radiation for screening people, objects, cargo and transports. RPMs have been deployed around the U.S. and other international borders, for the interdiction of radioactive materials that are deemed as threats. Instruments such as RPMs need to be deployed and operated in a specified manner in order to correctly execute their purpose. The deployment and operation of RPMs can be based on national and international standards and specifications. This document provides guidance on the appropriate deployment of RPMs for State and Local Government use, specifically for Ludlum Technology model 4500 RPMs provided by the Department of Homeland Security. 


\section{Acronyms and Abbreviations}

$\begin{array}{ll}\text { ANSI } & \text { American National Standards Institute } \\ \text { DOE } & \text { U.S. Department of Energy } \\ \text { IAEA } & \text { International Atomic Energy Agency } \\ \text { NORM } & \text { Naturally Occurring Radioactive Material } \\ \text { PNNL } & \text { Pacific Northwest National Laboratory } \\ \text { RPM } & \text { Radiation Portal Monitor } \\ \text { RSP } & \text { Radiation Sensor Panel }\end{array}$




\section{Contents}

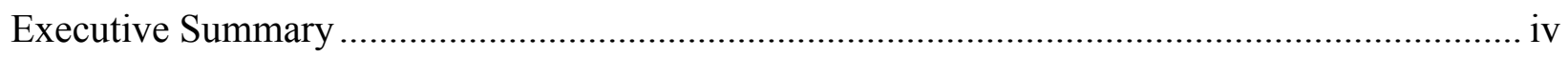



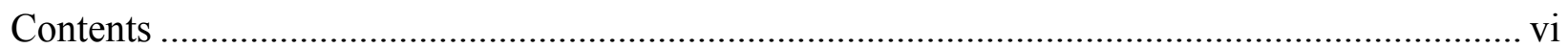

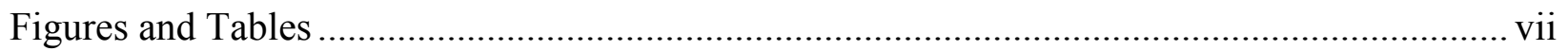

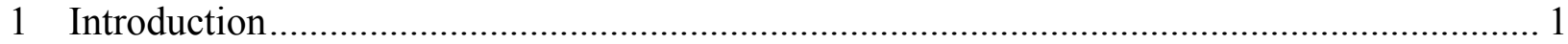

2 National and International Standards and Specifications .............................................. 3

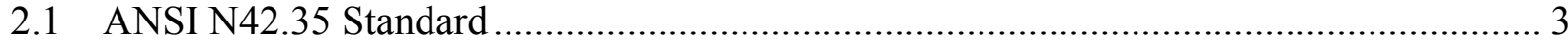

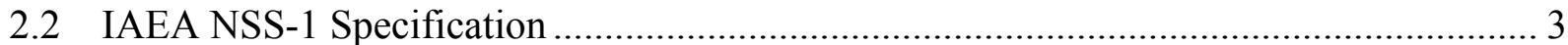

2.3 U.S. Customs and Border Protection RPM Systems ................................................ 4

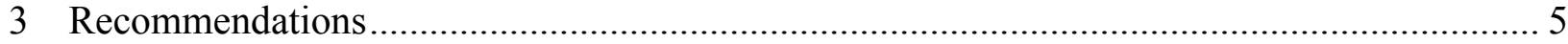

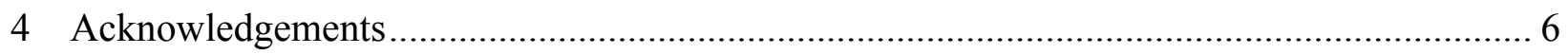

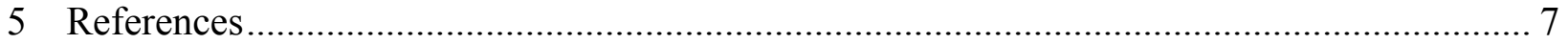




\section{Figures and Tables}

\section{Figures}

Figure 1. Example RPM cargo configuration. [Kouzes 2003] ................................................ 2

\section{Tables}

Table 1. Activity values for gamma ray and neutron sources. [ANSI 2006] ............................. 3

Table 2. Activity values for gamma ray and neutron sources used in IAEA NSS-1................... 4 


\section{Introduction}

Radiation portal monitors (RPMs) are commonly used at international border crossings to detect illicit transport of radioactive material, including special nuclear material suitable for nuclear weapons [Kouzes 2005]. RPMs are effective tools for the detection of the illicit movement of radioactive materials, whether threat materials or unintended contamination. RPMs are used to determine the presence of radioactive materials by detecting the gamma rays and neutrons emitted from those materials, generating alarms when radioactivity above some threshold is detected. Some cargo contains naturally occurring radioactive material (NORM) that triggers what are referred to as "nuisance" alarms, since they are not deemed as a threat.

A RPM typically consists of two to four Radiation Sensor Panels (RSPs) positioned on opposite sides of a lane through which a person, vehicle or container passes. A Control Box provides the basic control and alarm functions for each individual RPM. A Supervisory Computer provides centralized storage of data and an overview of operations. The exact system configuration varies according to the infrastructure and daily operations at each RPM site. Figure 1 shows a conceptual schematic of a cargo screening RPM configuration with RSPs located on both sides of multiple vehicle lanes.

When a RPM is deployed, the geometry is configured for the application and site. Two RSPs are used, one on each side of a lane, for personally owned vehicle deployments. Four RSPs, two on each side of a lane, are typically used for screening of cargo in trucks. The spacing between RSPs across a lane is constrained to specified values based on the application and local conditions.

Operation of an RPM requires the setting of parameters that determine the conditions under which the RPM will generate alarms. Many of these parameters are specified by routine operating values. The specific alarm thresholds are established by a combination of source measurements at each specific site, computed quantities, and policy decisions.

Alarm thresholds are typically set using "sigma multiplier" values, where sigma is the square root of the one-second averaged background rate. In this way, the alarm thresholds adapts to changes in average radiation background. Sigma values for gamma ray and neutron gross count alarms are typically in the range from 5 to 30 .

This document describes the requirements for deployment and operation of RPM systems intended for State and Local Government use as the primary screening tool for the detection of radionuclides within intermodal cargo containers, trucks, and passenger vehicles. These requirements are based on national and international standards and specification. Pacific Northwest National Laboratory (PNNL) has been involved in the specification, testing and deployment of RPM systems domestically and internationally since 2002. This perspective is brought to the recommendations made in this document. 


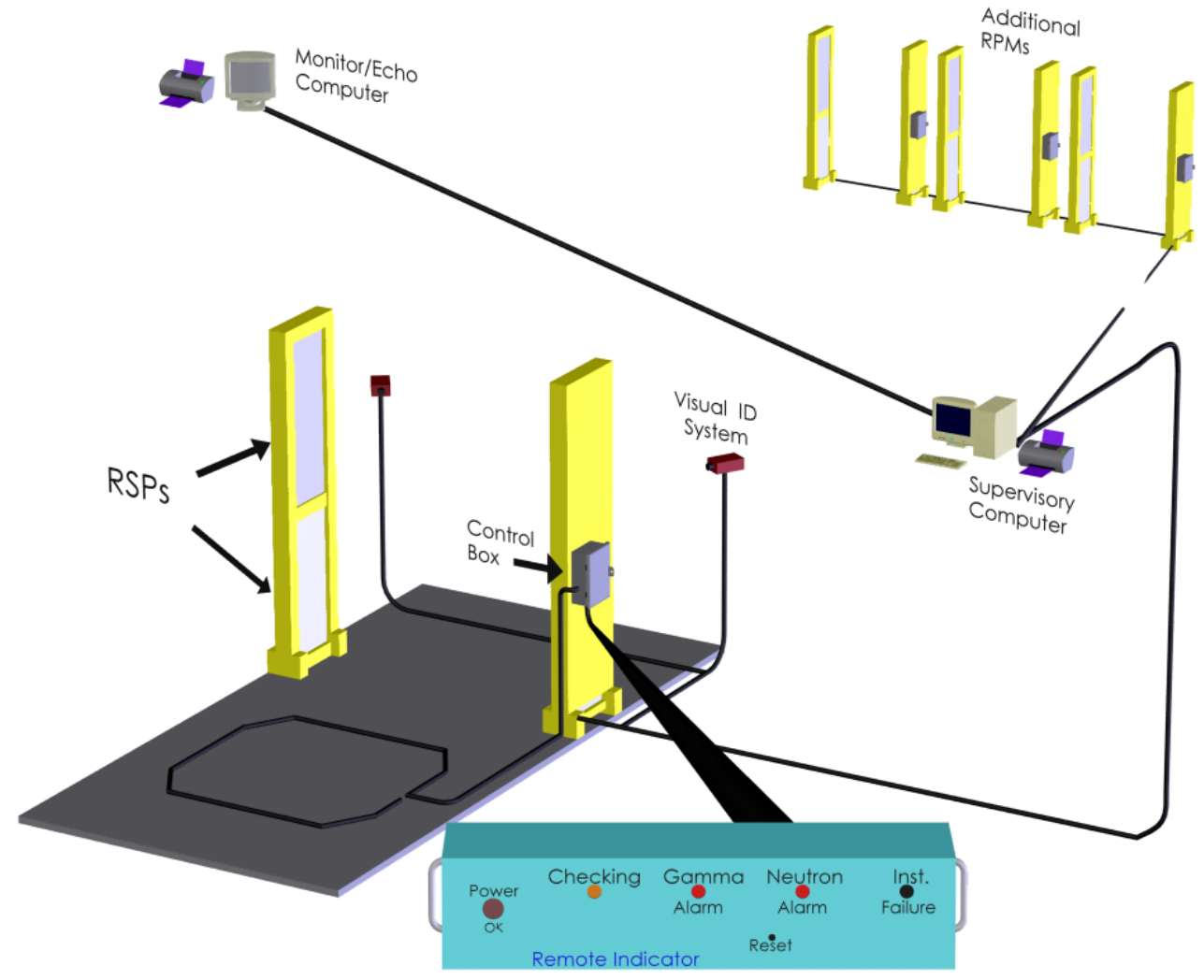

Figure 1. Example RPM cargo configuration. [Kouzes 2003] 


\section{National and International Standards and Specifications}

Since RPMs are common instruments used at international border crossing in the U.S. and around the world, standards and specifications have been developed by recognized organizations.

The American National Standard Institute (ANSI) developed a testing standard N42.35 entitled American National Standard for Evaluation and Performance of Radiation Detection Portal Monitors for Use in Homeland Security [ANSI 2006]. As a testing standard, it is intended for establishing basic requirements for RPM systems that can be tested and compared between vendors. It is not intended as a deployment specification, but any RPM system deployed in the U.S. needs to meet the ANSI N42.35 requirements.

The International Atomic Energy Agency (IAEA) developed a specification NSS-1 entitled Technical and Functional Specification for Border Monitoring Equipment that includes testing and deployment requirements for RPM systems [IAEA 2009]. The NSS-1 and ANSI N42.35 have been "harmonized" by the international community so that the basic requirements are consistent across these documents.

\subsection{ANSI N42.35 Standard}

The ANSI N42.35 standard [ANSI 2006] provides a large set of requirements for RPM systems, including those for radiation detection, environmental performance, electrical and electromagnetic performance, and mechanical performance. There are standard testing conditions established. For the purpose of testing, the RSPs of the RPM are placed $5 \mathrm{~m}$ apart, and the speed of $2.2 \mathrm{~m} / \mathrm{s}$ is used for source movements.

For ANSI testing, the RPM gross count alarm threshold is set for a 1 in 1000 false alarm rate (which is typically too low to be usable in a field deployment). Only the gross count alarm threshold capability of the RPM system is utilized in ANSI testing. Under these conditions, typical source tests require the RPM to alarm 59 out of 60 trials. Table 1 provides the sources used in ANSI N42.35 testing.

Table 1. Activity values for gamma ray and neutron sources. [ANSI 2006]

\begin{tabular}{|ll|}
\hline Radionuclide & Type test and evaluation test source activity \\
\hline${ }^{57} \mathrm{Co}$ & $5 \mu \mathrm{Ci}(185 \mathrm{kBq})$ \\
${ }^{133} \mathrm{Ba}$ & $14 \mu \mathrm{Ci}(518 \mathrm{kBq})$ \\
${ }^{137} \mathrm{Cs}$ & $16 \mu \mathrm{Ci}(592 \mathrm{kBq})$ \\
${ }^{60} \mathrm{Co}$ & $7 \mu \mathrm{Ci}(259 \mathrm{kBq})$ \\
${ }^{232} \mathrm{Th}$ & $14 \mu \mathrm{Ci}(518 \mathrm{kBq})$ \\
${ }^{241} \mathrm{Am}$ & $47 \mu \mathrm{Ci}(1.74 \mathrm{MBq})$ \\
${ }_{\text {Neutron }}\left({ }^{252} \mathrm{Cf}\right)$ & $2 \times 10^{4} \mathrm{n} / \mathrm{s} \pm 20 \%$ \\
\hline
\end{tabular}

\subsection{IAEA NSS-1 Specification}

The IAEA NSS-1 specification includes testing and deployment requirements for RPMs [IAEA 2009]. The specification provides many requirements on the hardware and software of the RPM. The RSPs of the RPM are to be placed $5 \mathrm{~m}$ apart and vehicle speed is to be limited to $2.2 \mathrm{~m} / \mathrm{s}$, which are the same requirements used in the ANSI standard. The false alarm probability is limited to 1 in 10,000 passages. Radiological performance is based on a specified absolute detection efficiency. In addition, dynamic test requirements must be passed. 
The dynamic tests requirements are intended to verify the overall system performance for gamma ray and neutron detection. The sources specified for testing are given in Table 2. The RPM is required to trigger a radiation alarm when the specified sources pass through the detection zone of the RPM. The ${ }^{137} \mathrm{Cs}$ source is the same activity as used in ANSI N42.35, but the ${ }^{57}$ Co source is about three times larger.

Table 2. Activity values for gamma ray and neutron sources used in IAEA NSS-1.

\begin{tabular}{|ll|}
\hline Radionuclide & Type test and evaluation test source activity \\
\hline${ }^{57} \mathrm{Co}$ & $16 \mu \mathrm{Ci}(600 \mathrm{kBq})$ \\
${ }^{137} \mathrm{Cs}$ & $16 \mu \mathrm{Ci}(600 \mathrm{kBq})$ \\
Neutron $\left({ }^{252} \mathrm{Cf}\right)$ & $1.2 \times 10^{4} \mathrm{n} / \mathrm{s} \pm 20 \%$
\end{tabular}

\subsection{U.S. Customs and Border Protection RPM Systems}

The deployment of over 1400 RPM systems from Ludlum Technology (Sweetwater, TX) and Leidos (Formerly SAIC, San Diego, CA) on the U.S. border has been executed by PNNL under the direction of U.S. Customs and Border Protection. The Ludlum 4500 systems, that comprise part of these deployments, are positioned with RSP spacing ranging from a recommended $4 \mathrm{~m}(13 \mathrm{ft}$.) up to $5 \mathrm{~m}(16.5 \mathrm{ft}$.), depending on local conditions and RPM type. Generally, RPMs are deployed as narrow as possible consistent with traffic lane usage.

RPMs undergo an initial calibration, and yearly thereafter, with radiation sources to determine the correct thresholds settings. All RPM systems use a gross count threshold, and cargo systems additionally use energy-windowing thresholds that improve sensitivity to threat sources. A spreadsheet is used to collect calibration data and to compute from this the threshold settings that are to be set in the Ludlum 4500 RPM systems. 


\section{Recommendations}

The basis for deployment of two-panel and four-panel RPMs for State and Local Government use should be the IAEA NSS-1 specification. The important deployment parameters that derive from this specification are:

- RSP to RSP spacing across a lane should be $5 \mathrm{~m}$ (16.5 ft.) or less

- RPM parameters other than gross count thresholds should be set to typical default values represented in the calibration spreadsheet

- Gross count alarm threshold for gamma rays should be determined using a ${ }^{57} \mathrm{Co}$ source of $16 \mu \mathrm{Ci}$ 


\section{Acknowledgements}

Pacific Northwest National Laboratory is operated for the United States Department of Energy under contract DE-AC05-76RLO 1830. 


\section{References}

[ANSI 2006] “American National Standard for Evaluation and Performance of Radiation Detection Portal Monitors for Use in Homeland Security," American National Standards Institute ANSI N42.35, National Institute of Standards and Technology, February 2006.

[IAEA 2009] International Atomic Energy Agency Nuclear Security Series No.1 Technical Guidance, "Technical and Functional Specification for Border Monitoring Equipment," Revision 1, Vienna, Austria, August 2009.

[Kouzes 2003] RT Kouzes, “Performance Specifications for Portal Monitors (Rev 6.7)," Pacific Northwest National Laboratory Report PIET-43741-TM-017, June 2003.

[Kouzes 2005] RT Kouzes, "Detecting Illicit Nuclear Materials," PNNL-SA-43674, American Scientist 93, pp. 422-427, September-October 2005. 


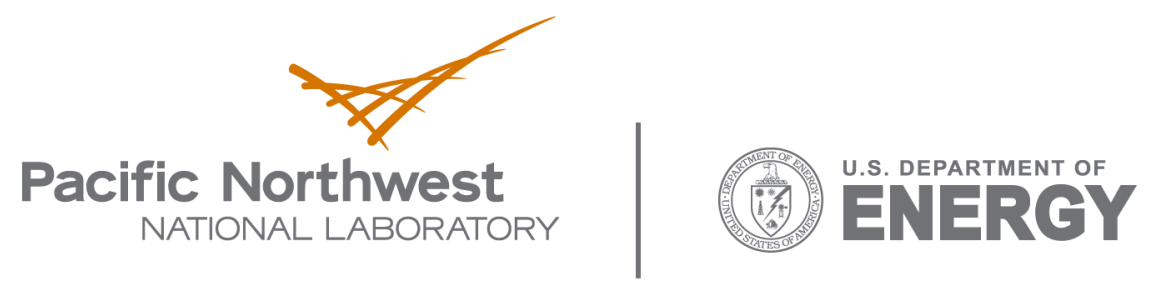

902 Battelle Boulevard

P.O. Box 999

Richland, WA 99352

1-888-375-PNNL (7665)

www.pnl.gov 